Final draft amended for publication.

\title{
Teaching Shakespeare with film adaptations
}

\section{Introduction}

The ready availability of popular film versions of Shakespeare plays on DVD and other digital formats, coupled with the rapid development in classroom technology over the past decade (Jewitt et al. 2009) have had the potential to radically change the traditional relationship between secondary school students and the printed playtext. Teacher surveys published over the past ten years (see for example, Batho 1998; Martindale 2008; Stibbs 1998) indicate that very nearly every English teacher complements the study of a set Shakespeare text at Key Stage 3 or $4^{1}$ with reference to a DVD or video adaptation. There is, however, much less empirical evidence about the use to which these moving image versions are commonly put: for instance, how teachers construct the cultural and historical relationship between playtext and adaptation within the classroom, or the way students are positioned as readers of the different textual modes. The purpose of this chapter is to explore some of the pedagogical possibilities raised by use of moving image Shakespeare and to consider some examples of teachers' practice taken from classroom-based research data.

\section{Background}

For nearly twenty years teachers in English state schools have been statutorily required to teach two Shakespeare plays to all students aged between 11 and 16 years. Precise forms of national assessment and testing of Shakespeare may have changed in the intervening years, but teacher concerns with issues of entitlement and access for the full range of student 'abilities' , particularly in urban comprehensive schools, have remained central (Kress et al. 2005). From the outset, Shakespeare was constructed in the National Curriculum as the de facto embodiment of English cultural heritage (Coles 2004; McEvoy 1991; Moore 2006), and very specifically as Literature (located within the programmes of study for reading), rather than as drama for performance (Franks 1999). Moreover, as Buckingham and Jones (2001) comment, successive UK governments have emphasised print-centred culture at the expense of new forms of media within education policies, a 
Final draft amended for publication.

position which is increasingly out of step with students' cultural lives outside of school. As noted by Burn (2010), film's relationship with English has been hindered historically by condescending attitudes towards the mass media inherited from Leavis (Leavis \& Thompson 1933), institutionalised during the last twenty years in curriculum struggles over cultural value and the primacy of print over visual production. According to a recent film industry report: 'film education is still on the margins of the formal curriculum' (BFI et al. 2008 p.8), despite a general acceptance by media educators that:

In the same way that we take it for granted that society has a responsibility to help children to read and write...we should take it for granted that we help children and young people to use, enjoy and understand moving images; not just to be technically capable but to be culturally literate too (BFI et al. 2008, p.1)

This statement reflects expanding concepts of literacy as a complex set of social practices situated in an increasingly technological world (see, for instance, Lankshear \& Knobel 2003). Yet this rich concept of literacy has only been partially translated into government policy documents. Thus, whilst the latest National Curriculum document (QCDA 2007) places moving image and multimodal texts within the reading curriculum and urges teachers to include 'non-linear and multimodal texts' in the range of texts students should encounter, lengthy lists of recommended literary print texts ('heritage' and 'contemporary') dominate the programme of study for reading. Film texts are absent from the National Curriculum's recommended canon of fiction, despite film having been established as a narrative art form for more than a century. Although teachers have 'shown the film of the book' to support the reading of English literary classics for decades, this practice is not officially recognised. So, in the National Curriculum's explanatory notes for reading at Key Stage 3 (QCDA, 2007, p.71) teachers are invited to explore Shakespeare in performance alongside reading the playtext, where performance includes theatre productions and classroom drama, but omits film productions. Significantly, only one of the GCSE examination boards in England and Wales has used the opportunity of curriculum and assessment changes at Key Stage 4 (as from September 2010) to offer scope for assessing students' responses to film versions of Shakespeare alongside the printed text (see below). 
Final draft amended for publication.

Considering how much Shakespeare is taught each year in English secondary schools, and therefore how many film versions of specific plays are presumably viewed, there has been surprisingly little research as to what is actually happening in classrooms. Evidence arising out of Rex Gibson's national Shakespeare project suggests little uniformity in the way teachers make use of film Shakespeare in the classroom (Gibson 1998), and, indeed, other commentators' conclusions are contradictory. Leach (1992), Goodwyn (2004) and Burn (2010) suggest that the most common practice is for teachers to show students a single film version, where the decontextualised film merely supports reading of the print text. This view is supported by Martindale's (2008) teacher survey which indicates that English teachers in the main regard film versions as little more than useful visual tools, affording easy access to the play in performance and an overview of plot and character, '...thereby allow[ing] more time to be spent on close study of the language in particular scenes' (p.20). In contrast, Stibbs' (1998) teacher survey conducted a decade earlier suggested the most common practice then to be critical comparison of clips taken from diverse screen productions. This is a practice exemplified in Marshall's more recent classroom-based research where a class explore divergent interpretations of Henry $V$ through a comparison of Olivier's and Branagh's film texts (Hodgen \& Marshall 2005). Kress et al's multimodal overview of English teaching in urban schools (2005) supplies additional qualitative evidence in its detailed description of a GCSE sequence of work based on Macbeth. In this the teacher combines film, drama and text: the teacher's strategy is to start the textual work with film, a cultural mode she assumes her students will find most accessible, then move to the reading of one brief witches' scene in depth (including a comparison of two moving image versions); this is followed by collaborative drama activities based on the scene, and then written coursework as the final stage of the process. Film is used to provide students with a sense of the play's plot, rather than being interrogated on its own cinematic terms. Kress et al comment on the extent to which the text of Macbeth becomes fragmented in this pedagogic model, where students' reading is heavily mediated by the teacher through worksheets and writing frames. The underlying assumption appears to be that students in urban classrooms are not capable of reading and responding to more than one scene from the printed Shakespeare playtext (particularly in the limited class-time available); film's status in this teaching sequence is positioned at the opposite end of the literacy spectrum, reduced to that of an undemanding, illustrated teaching aid. 
Final draft amended for publication.

A radically different relationship between film and playtext is constructed by Durran and Morrison (2004). In their work in a Cambridge comprehensive school, book and film (in this case, Macbeth and Romeo and Juliet) are afforded parity and taught side by side:

Film does not just serve the study of literature...each film version asks students to consider its own textual structure, and the reasons for its construction (Durran \& Morrison 2004, p.19)

Students analyse stills taken from different moving image versions of the play and explore the 'grammar of shots in sequence' (p.20). Provided with laptops, students are positioned as active readers of digital film text, and invited to navigate it in a non-linear fashion. Not only that, this study suggests that systematic analysis of film, an exercise in 'close technical reading - both of film and of Shakespeare' (p.17), encourages students to study the printed playtext more closely, a conclusion leant support by Bousted and Ozturk (2004) in their work with undergraduates reading Silas Marner alongside a film version. Burn (2010, p.356) concludes that this kind of comparative teaching, drawing on both media and literary critical traditions, 'implies a parity of cultural value, rather than a hierarchy privileging literature'.

\section{Classroom-based research}

I want to turn now to look at some examples from my own classroom-based research and focus on the way four English teachers use film when teaching specific Shakespeare plays. In my wider research, I am interested in considering the ways in which Shakespeare is constructed through competing discourses in the secondary classroom, and what sense students make of it. Samples of practice discussed here are selected from the body of data collected for this wider research project. In total I observed nearly thirty hours of English lessons in two contrasting London comprehensives, with a focus on two year 9 classes studying Macbeth and two year 10 classes, studying Henry $V$ and Romeo and Juliet respectively. The lessons were video-taped, transcribed, coded then analysed thematically (Miles \& Huberman 1994). The four teachers, ${ }^{2}$ whose experience ranges from newly qualified status to long-established head of department, were interviewed separately at the end of the sequence of lessons; these interviews were recorded, transcribed and similarly 
Final draft amended for publication.

analysed. I particularly want to focus here on the work of the two year 10 teachers, although within the scope of this chapter I am only able to offer glimpses of key moments from my classroom data.

All four teachers in my sample make use of film versions of the Shakespeare play under study and in interviews all are in complete agreement that 'a decent film version' is a crucial aspect to successful Shakespeare teaching at KS3 and 4. What might be surprising is that, despite the availability of a number of alternative productions of each play, each teacher adheres to a single version for use with their class. Marie ${ }^{3}$ shows Polanski's Macbeth (1971) with her mixed attainment year 9 class; Felicity uses the 1978 RSC version of Macbeth (dir. Trevor Nunn) with her middle set year 9; Beth shows Kenneth Branagh's 1989 film of Henry $V$ to her mixed attainment year 10 group; and Pip's middle set year 10 class watch Baz Luhrmann's 1996 film, Romeo + Juliet. In contrast to practice described in research elsewhere (see above), in the lessons I observed none of the teachers make comparisons across available alternatives, even to look at how key scenes have been interpreted by different directors. In effect, Marie, Felicity and Pip show the film/video version in a fairly concentrated unedited block, spanning two or three lessons with little or no accompanying discussion. Marie's class watch the whole of Macbeth while she is absent during two cover lessons before beginning the unit of work on the play. Felicity's class watch the video of Macbeth once they have begun to read the opening scenes of the play, after some preliminary work on Shakespeare's life and times. Pip reads the opening scene of the play after some discussion about film conventions, then shows the opening sequence of Baz Luhrmann's film; the class get to watch the whole film between lessons four and six. In contrast, Beth stages the viewing of the film version of Henry $V$ across a number of lessons so that it runs more in sequence with the small amounts of reading her class undertake. My interviews with the teachers indicate that there is little consensus between them as to how each film might be organised structurally within the series of lessons and that this aspect of their Shakespeare teaching is less consciously theorised than others. None of the teachers read more than a third of the playtext with their classes - and the two Year 10 classes read considerably less. 
Final draft amended for publication.

Both Baz Luhrmann's Romeo + Juliet and Roman Polanski's Macbeth prove to be popular with their student audiences, yet the status of moving image texts in these classrooms is an uncertain one. Because the focus of study ultimately remains the literary text (as is demanded by the specific national assessment systems in place at the time of the research) it results in each teacher performing a sleight of hand, whereby students encounter the majority of the play through film but write a conventional 'lit crit' essay about fragments of printed text as if they had read the whole. Hence, students who assume the film adaptation is 'the' version have to be corrected when preparing their assignments and reminded of the primacy of the printed text.

Pip and Beth appear to construct Romeo and Juliet and Henry $V$ in film terms for their year 10 students right from the start. In Pip's opening lesson she invites her students to recall films they have seen which have dramatic opening scenes before she shows them Luhrmann's interpretation of Romeo and Juliet Act 1 scene i. Although the viewing is prefaced by asking the students to notice how the film-maker dramatises the opening scene, and to consider the way 'the hate between the two families is set up', Pip's subsequent whole-class questioning is entirely focused on impressions of character:

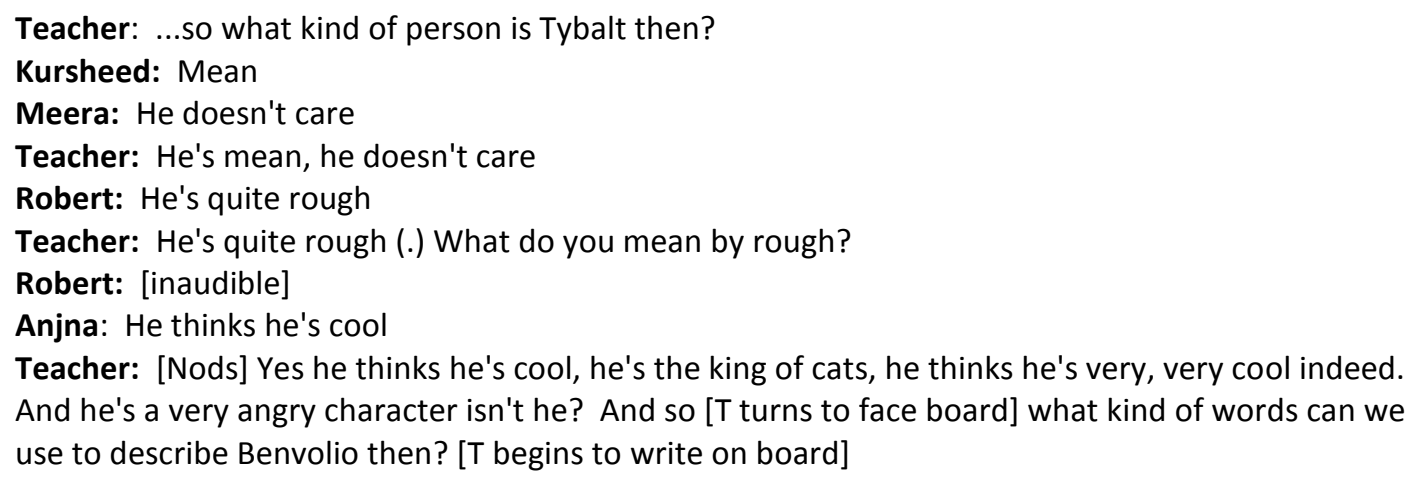

This extract is typical in the way the students are expected to draw generalised, quasiliterary conclusions about character and events from a very specific film adaptation. The Luhrmann film remains a continuing reference point in Pip's classroom throughout the series of lessons, but it is always to be mined for plot information or character recognition and rarely, if ever, analysed as a film. Pip resolutely refers to 'the play' in class discussions even though students' comments (such as a student suggesting that Mercutio 'looked like 
Final draft amended for publication.

he was on drugs'), indicate it is the film text that they are cross-referencing, even after they have read parallel extracts from the playtext.

Perhaps not surprisingly for an experienced Media Studies teacher, Beth introduces students to Henry $V$ through the medium of film. In the first lesson I observed (the third lesson in the teaching sequence) Beth asks students to deconstruct the image of King Henry's first entrance in the play (at the opening of Act 1, scene 2 ) using a still photo captured from Branagh's film version. Students are positioned by Beth as 'viewers of Henry', a perspective that enables them to distance themselves from stock literary responses around 'character'. Consequently, their contributions focus on the trappings of kingship and on this entrance as a dramatic moment:

Teacher: ...Other words people came up with? Richard?

Richard: Powerful

Teacher: Brilliant! Why powerful?

Richard: Because he made an impression, he's coming out of darkness, the doors opening, it's lightening him up

Dexter: He's wearing a robe

Teacher: He's wearing a what?

Dexter: [gestures with his hands] He's wearing all robes, like a cape -

S: [interrupting, humorous tone] Cape! He's not Superman, you know!

Dexter: [deliberately finishing what he was saying] they make him look scary

Ss: [several start to shout out]

Teacher: [amused] Because robes are always scary? [she gestures next student] OK, guys! Ade, what else have you got, please?

Ade: I just put powerful and scary

Teacher: Powerful and scary. OK. Bode, what did you put?

Bode: I put dark, manly figure

Teacher: Brilliant, yep, OK. Cem?

Cem: The light's on him, it means God's on his side

Teacher: Fantastic. I really like that: the light's on him so God's on his side. I like that one a lot. OK, Karen.

Karen: Secrecy because he's in shadow

Teacher: Brilliant, secrecy, I like that. [A few Ss call out] No, don't call out! We need to hear comments. Yeah, Bode?

Bode: Shady

Teacher: Why shady?

Bode: Because you can't really see his face, yeah. You can only see bits where the light comes in

By working multimodally, students are co-constructing an initial reading of Henry which 
Final draft amended for publication.

begins to capture the ambiguities inherent in Shakespeare's king figure, ambiguities that help explain the variant (and sometimes contradictory) readings of the play. Later in the same lesson, after watching the beginning of the film on DVD, Beth outlines reasons for the English going to war; she is able to explicitly build on Cem's comment about God being on Henry's side, developing a sense that interpretation in this classroom is produced dialogically, out of interaction between all parties. Beth's approach is unique amongst my sample of four teachers in decentring Shakespeare's text: Branagh's film version quite consciously remains the key reference point throughout the observed lessons. This helps to shift the act of reading away from conventional parameters of literary meaning in terms of character, plot and feature spotting. Students' impressions of Henry are not characterbased in the conventionally idealist sense (ie., how he comes across as a person). Instead, students are encouraged to approach the play as a performed drama, and to consider Henry as a dramatic figure whose actions have significant political, social and personal consequences.

In Beth's classroom role plays and improvisation arise as an extension of watching the film. At times students are asked to predict events or decisions through drama, at others to develop an aspect from a section of the play they have watched on film. For example, during one lesson Beth asks one student to be Henry and another to be the French Ambassador presenting the King with a mystery gift:

Teacher: Right, OK, Henry (.) Henry now comes in, OK, and I want someone here to stand at the front and be Henry. Yeah. OK, Owsun. [Owsun gets up and moves to front] And I want somebody else to come [turns to Owsun] come and stand over here where there's a bit of space. Ok, Henry has just come in (.) walked in through this door. He's now um (.) he's now standing there and the French ambassador (.) I need a volunteer to be the French ambassador [a few Ss make stereotypical French sounds] don't worry about the language, you're going to give Henry a present.

[Several Ss put up hand and call out]

Unur: I don't mind!

Teacher: OK, Unur [S gets up and come to the front] OK, the French ambassador... [T hands over large box] How do you think the French ambassador is feeling as he walks up to Henry to give this present?

Unur: Scared and nervous.

Teacher: Scared and nervous. Right. Why are you feeling scared and nervous?

Unur: Because he's afraid he might get killed.

Teacher: And he's representing his country. Kadife what were you saying? 
Final draft amended for publication.

Kadife: Might get killed.

Teacher: Might get killed. Good.

Richard: He shouldn't, he's an ambassador.

Teacher: Yup, he shouldn't do, because he's an ambassador, he should be protected, but he's a bit worried. OK. What do you think (.) Graham, what do you think is the message you, er, he is going to say? He's already had a message that Henry wants to invade France. What do you think the French ambassador is going to say to that?

Ss: [various, making stereotypical French sounds]

Teacher: Listen! Dexter?

Dexter: We don't want war, we want to make peace.

Teacher: We don't want war, we want peace, OK. But what else might, probably, the King of France think if the King of England writes and says, I want your country?

S: [in French accent] Idiot!

Teacher: Idiot. Perhaps.

Ade: War!

Students are next invited to predict what might be in the parcel (suggestions include 'a bomb', 'a head'), then Unur, in role as the Ambassador, passes over the box, and Owsun is directed to open the present (which he does in suitably dramatic fashion). The teacher leads a whole-class discussion as to what tennis balls might symbolise; all students are then asked to jot down what they think Henry's response is likely to be. These ideas are read out to the class, following which students watch this scene on film and then have a look at photocopied extracts from Henry's actual speech:

Teacher: ...We'll hear a few ideas, what's Henry going to say and then (.)...I'm then going to very, very quickly show you a little bit of what Henry does actually say...

Ade: [in role] 'He's suggesting I should go play tennis. This is a great insult. If he wants to play with me, we'll play on the battlefield'.

Teacher: Brilliant. Yeah. [indicates another S with hand up] Right, OK, Dexter? (2) OK, listen!

Dexter: [in role] 'How dare you! The cheek! I should kill you for the thought against a King!' Teacher: Good. Right, Karen?

Karen: I don't want to

Teacher: Go on! Or shall I read it then? [moves across to Karen. Reads her work] 'Is this a joke? OK, if he wants to stick tennis balls, um, then (2) [she consults Karen] off with his pighead. He's got another think coming! I want his head and when I do, I'll play tennis with it and let that be a warning to him!' OK, excellent!

Improvisation, role-plays and film are inextricably linked here in the reading process, often with students drawing on their own experiences and cultural knowledge within the collaborative framework of drama. For instance, when students are in small groups 
Final draft amended for publication.

considering what a leader might say to rally their troops, Kadife asks Beth: 'Were people living in England in them days, were they all Christians?'. Cem pursues this line of thought and asks Beth what would have happened in Henry's day to someone who was not a Christian. Later, adopting the role of leader, Unur incorporates the words, 'Do it in the name of Allah' into his motivational speech to the class. These students are simultaneously behaving as social actors and dramatic actors (Franks 1996; Neelands 2009), a fusion which has the potential to help bridge the gap between the Shakespeare text and students' own cultural understandings - a fusion I would argue which is made easier by the decentring of the 'sacred text'.

\section{Conclusions}

Echoing findings from Kress et al's research (2005), access as a concept is a key concern for each of these London teachers, and it underpins every aspect of their approach to Shakespeare, including pedagogy and film selection. For example, Beth chooses Branagh's version of Henry $V$ because it is 'pretty accessible'; Pip talks about Luhrmann's Romeo + Juliet in terms of modernisation and relevance, and, along with Marie, states that a film aids pupils' understanding of the plot and characters. Felicity is critical of the RSC video production of Macbeth for being less accessible (she calls it 'the big turn-off') and in interview regrets using it with her class, suggesting that this televised stage production is appropriate for top sets only. Across these classrooms film's role is subordinated as a cultural form, pressed into service as a simplified substitute for the 'real thing'. Holderness (1985) suggests that the act of adaptation, reconstructing Shakespeare for screen, is potentially a radical process which disrupts conventional ways of reading and thinking about the text. But the way in which film is employed in these classrooms may well achieve the opposite, by suggesting that this specific production represents 'the' authoritative interpretation of the text:

Conventional ways of using film with Shakespeare present some problems...watching a single version of a Shakespeare play can flesh out the story for pupils in a way that constrains the imagination...such films are still generally read as extended, linear works, positioning the viewer through the force of narrative (Durran \& Morrison 2004, p.17) 
Final draft amended for publication.

There is a school of thought that Shakespeare's printed plays are merely 'pre-texts' (Wheale 1991, p.214), incomplete in themselves until transformed by performance (Reynolds 1991). My interviews concur with Martindale's questionnaire data (2008) indicating that English teachers appreciate the importance of performance, and welcome the benefit of film in providing easy classroom access to a professional performance of the complete play. That teachers generally do not draw students' attention to the differences between film and theatre as performance modes is problematic, particularly with, say, Baz Luhrmann's Romeo + Juliet which with its high-tech digital editing techniques shifts the playtext into a multimodal space more closely related to pop videos and electronic games geared for the teenage market. Shakespeare DVDs that can be viewed non-linearly on large or small screen, including laptops have the capacity to completely change the concept of performance, and of the play's relationship to its audience (Worthen 2007). This in itself could be a fruitful area for exploration in classrooms, along with comparisons of the playtext and the screenplay.

Teachers' appreciation of film versions of Shakespeare does not in itself raise films' status as texts. Despite frequent references to film and television texts by teachers in the classroom, moving image versions of specific plays are rarely if ever interrogated in their own terms. Ultimately literary culture is tacitly afforded superior status in each of the classrooms I researched. Although Pip begins the unit of work on Romeo and Juliet by making links with her students' existing cultural knowledge of popular film, this is abandoned once the text itself is introduced. Even in Beth's classroom, Branagh's film text is supplanted by fragments of printed text once students begin to write their (heavily scaffolded) GCSE coursework essay. Moreover, the notion of textual authority is strongly marked in these classrooms. Despite at least three of the four teachers clearly feeling committed to enabling students to interpret the play for themselves, the majority of the lessons I recorded in both schools frequently position the students passively in the reading process and strongly suggest that there is ultimately a 'correct' way of thinking about the play, one which students need to reproduce in their exam or coursework essays. My observations of teachers working within curricular and assessment constraints provide a glimpse into just how difficult it is to avoid reproducing authoritative readings of Shakespeare's plays in the classroom, and the 
Final draft amended for publication.

relegation of film as a low-status medium to support the reading of high status printed text. When interviewed, two of the teachers are even slightly defensive about showing the film, suggesting that this is somehow not a valid part of English lessons. For example, Pip says, 'You always feel a bit of a cop-out teacher if you're showing the video, but I do think they do get so much out of it'. A common theme running through each of the teacher interviews is that film's main purpose is to provide a sense of the plot and the main characters, so that only small sections of the printed text need to be read. The phrase 'filling in' is used in this context by more than one teacher, putting film very much in its place.

Any assessment system that purely focuses on the printed text will tend to treat a Shakespeare play as a piece of literature, rather than as a playtext for performance. My research indicates that it also results in a degree of dishonesty whereby teachers substitute the film for the printed text in lessons, yet construct essay assignments for their students which for the most part rely on them ignoring the film version. Therefore it is an interesting development that one GCSE exam board (the Oxford and Cambridge and RSA Examination Board, or OCR) has from Autumn 2010 introduced assessment of a set Shakespeare play which explicitly raises the status of film adaptations by requiring students to compare playtext and performance text (moving image, audio or live performance). Support materials produced for the OCR by Film Education (2010) provide teaching resources underpinned by a clear rationale:

Film...is a popular medium and by teaching young people the critical skills with which to deconstruct both directors' interpretations of Shakespeare's texts and the texts themselves, teachers have an opportunity to approach the subject afresh. The combination of classic texts reconstructed by modern filmmakers goes to the heart of the debate about the position of Shakespeare in schools and provides teachers with a rich source of stimulus material for their students (p.5)

Film Education's approach to the study of Shakespeare and film assumes that the reading process is both active and critical. The teaching support materials exemplify this approach, including, inter alia, comparison of book and film as commercial objects; a focus on differences between film and theatre language and techniques (for example, how 'character' is constructed in each medium); and exploration of historical perspectives on notions of cultural value. 
Final draft amended for publication.

New technologies offer the potential to make diverse 'Shakespeares' available in the classroom, multimodal forms which have the capacity to subvert the kind of 'heritage' Shakespeare beloved of politicians. There is a rich seam of literary and cultural understanding to be mined within the classroom in comparing the ways in which playscripts have been adapted and reshaped according to the specific medium. This helps to place emphasis on audience and purpose, and on the ways different productions are received rather than seeking 'essential' meanings residing in the text (Clarke 1995). Such an approach would serve to shift moving image adaptations to the centre of pedagogic attention, so that the specific social and historical context of production is given prominence (Goodwyn 2004). Students can begin to explore how Shakespeare has been re-read and reinterpreted at different historical moments, and adapted to fit new modes of production whether theatrical, literary or digital. Not only is this pedagogy based on a 'model of literacy that can travel across semiotic modes and cultural forms' (Durran \& Morrison 2004, p.17), but I would argue it comes much closer to meeting the National Curriculum's declared aim of helping students appreciate why Shakespeare's plays have remained popular and influential over time.

\section{Notes}

1. Key Stage 3 (KS3) covers age range 11-14 years, classes 7-9; Key Stage 4 (KS4) covers age-range 14-16 years, classes 10 and 11 .

2. One of the teachers originally trained as a drama teacher; two have substantial experience as Media Studies practitioners.

3. All names of teachers and students have been anonymised.

\section{References}

Batho, R. (1998) Shakespeare in secondary schools, Educational Review, 50(2), 163-172. BFI, Film Education, UK Film Council \& EMC (2008) Film: twenty-first century literacy, BFI, Film Education, UK Film Council, EMC.

Bousted, M. \& Ozturk, A. (2004) "It came alive outside my head." Developing literacies through comparison: the reading of classic text and moving image, Literacy, 38(1), 52-57. 
Buckingham, D. \& Jones, K. (2001) New Labour's cultural turn: some tensions in contemporary educational and cultural policy, Journal of Education Policy, 16(1), 1-14.

Burn, A. (2010) A very long engagement: English and the moving image, in: D. Wyse, R. Andrews \& J. Hoffman (Eds) The Routledge international handbook of English, language and literacy teaching (Abingdon, Routledge), 354-366.

Clarke, S. (1995) Is 'NC' English never changing? Shakespeare and the new Information Technologies, English in Education, 29(2), 12-19.

Coles, J. (2004) Much ado about nationhood and culture: Shakespeare and the search for an 'English' identity, Changing English, 11(1), 47-58.

Durran, J. \& Morrison, C. (2004) From page to screen and back again: teaching literature through moving image; teaching moving image through literature, English Media Drama, 16-22.

FilmEducation (2010) OCR GCSE English Literature, Unit 661: Shakespeare and film. (Available online at: http://www.ocr.org.uk/download/sm/ocr 48119 sm gcse unit a661 film res.pdf accessed 10:12:10).

Franks, A. (1996) Drama education, the body and representation (or, the mystery of the missing bodies), Research in Drama Education, 1(1), 105-119.

Franks, A. (1999) Where the action is: how drama contributes to the art of the teaching and learning of English, English in Education, 33(2), 39-49.

Gibson, R. (1998) Teaching Shakespeare (Cambridge, Cambridge University Press).

Goodwyn, A. (2004) English teaching and the moving image (London, Routledge Falmer).

Hodgen, J. \& Marshall, B. (2005) Assessment for learning in English and mathematics: a comparison, The Curriculum Journal, 16(2), 153-176.

Holderness, G. (1985) Radical potentiality and institutional closure: Shakespeare in film and television, in: J. Dollimore \& A. Sinfield (Eds) Political Shakespeare (Manchester, Manchester University Press), 182-201.

Jewitt, C., Bezeimer, J., Jones, K. \& Kress, G. (2009) Changing English? the impact of technology and policy on a school subject in the 21st century, English teaching: practice and critique, 8(3), 8-20.

Kress, G., Jewitt, C., Bourne, J., Franks, A., Hardcastle, J., Jones, K. \& Reid, E. (2005) English in urban classrooms: a multimodal perspective on teaching and learning (London, Routledge Falmer).

Lankshear, C. \& Knobel, M. (2003) New literacies: changing knowledge and classroom learning (Buckingham, Open University Press).

Leach, S. (1992) Shakespeare in the classroom (Buckingham, Open University Press).

Leavis, F. R. \& Thompson, D. (1933) Culture and environment (London, Chatto and Windus).

Martindale, S. (2008) Shakespeare on film: viewing Shakespeare inside the classroom and out,

English Drama Media, 10, 19-22.

McEvoy, S. (1991) The politics of teaching Shakespeare, English in Education, 25(3), 71-78.

Miles, M. \& Huberman, M. A. (1994) Qualitative data analysis (Beverly Hills, Sage).

Moore, A. (2006) Curriculum as culture: entitlement, bias and the Bourdieusean arbitrary, in: A.

Moore (Ed) Schooling, culture and curriculum (London, Routledge), 87-99.

Neelands, J. (2009) Acting together: ensemble as a democratic process in art and life, Research in

Drama Education, 14(2), 173-189.

QCDA (2007) The National Curriculum: English, (London, Qualifications and Curriculum

Development Agency).

Reynolds, P. (1991) Unlocking the box: Shakespeare on film and video, in: L. Aers \& N. Wheale (Eds)

Shakespeare in the changing Curriculum (London, Routledge), 189-203.

Stibbs, A. (1998) Between desk, stage and screen: 50 years of Shakespeare teaching, Educational Review, 50(3), 241-248.

Wheale, N. (1991) Scratching Shakespeare: video-teaching the Bard, in: L. Aers \& N. Wheale (Eds) Shakespeare in the changing curriculum (London, Routledge), 204-221. 
Final draft amended for publication.

Worthen, W. B. (2007) Performing Shakespeare in digital culture in: R. Shaughnessy (Ed) The Cambridge companion to Shakespeare and popular culture (Cambridge, Cambridge University Press), 227-247. 